LOPES SJ; BRUM B; SANTOS VJ; MELO EFRQ; SANTOS OS; COUTO MRM. 2007. Área foliar e número de flores de nastúrcio sob duas densidades de plantio. Horticultura Brasileira 25: 159-163.

\title{
Área foliar e número de flores de nastúrcio sob duas densidades de plantio
}

\author{
Sidinei José Lopes ${ }^{1}$; Betânia Brum ${ }^{1,4}$; Valdecir José dos Santos ${ }^{1}$; Evanisa Fátima RQ Melo²; Osmar S dos \\ Santos'; Mara Rúbia M Couto ${ }^{3}$ \\ ${ }^{1}$ UFSM, Dep ${ }^{\text {to }}$ Fitotecnia, Av. Roraima, s/n, 97105-900 Santa Maria-RS; ${ }^{2}$ UPF, Campus I, BR 285, km 171, $99001-970$ Passo Fundo-RS;

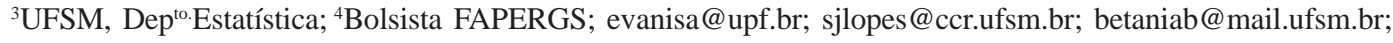 \\ mararubiacouto@bol.com.br
}

\section{RESUMO}

Estimou-se a área foliar do nastúrcio (Tropaeolum majus L.) por métodos não destrutivos e determinou-se a variação temporal da área foliar e do número de flores sob duas densidades de plantas em dois experimentos, em estufa plástica, na UFSM. No primeiro experimento calculou-se a área foliar a partir da análise de 50 folhas, provenientes de dez plantas, através de imagens digitais, relacionandoa à estimativa da área foliar feita a partir de discos foliares. Correlacionou-se também a área foliar à medida de quatro diagonais das folhas: medida sobre a nervura principal, perpendicular à nervura principal e duas medidas transversais à nervura principal. Obteve-se coeficiente de determinação $\left(r^{2}\right)$ de $0,94(p<0,05)$ entre as medidas obtidas através de discos foliares e de fotos digitais. A área foliar $=$ $0,8906 x^{2}$, em que $x=$ medida sobre a nervura principal, apresentou o maior coeficiente de determinação $\left(r^{2}=0,99 ; p<0,05\right)$, das quatro diagonais testadas. No segundo experimento, foram utilizadas duas densidades de plantio: $0,60 \mathrm{~m}$ entre plantas $\mathrm{x} 0,50 \mathrm{~m}$ entre linhas, $\mathrm{e}$ $0,30 \times 0,25 \mathrm{~m}$. De cada densidade, estimou-se a área foliar da planta através da equação ajustada com a medida da diagonal principal de todas as folhas maiores que $5 \mathrm{~cm}$ de quatro plantas, ajustando-se modelos logísticos para a variação temporal da área foliar e do número de flores por planta (avaliado a partir de flores colhidas em 1 $\mathrm{m}^{2}$ ). A menor densidade de plantio proporcionou maior área foliar por planta $\left(6932 \mathrm{~cm}^{2}\right)$, com máximo em 47 dias após o plantio (DAT) e 695 graus-dia (GD), que a maior densidade $\left(3129 \mathrm{~cm}^{2}\right)$, que apresentou máximo 42 DAT e 622 GD. O florescimento ocorreu antes das plantas atingirem o máximo de área foliar e a maior produção de flores foi obtida na maior densidade de plantas.

Palavras-chave: Tropaeolum majus, modelos de crescimento, densidade de plantas.

\section{ABSTRACT \\ Leaf area and flower number of nasturtium in two plant densities}

Two experiments were conducted in a plastic greenhouses in Santa Maria, Rio Grande do Sul State, Brazil, to estimate the nasturtium (Tropaeolum majus L.) leaf area through non destructive methods, as well as to study the leaf area and flower number variation in time, in two planting densities. In the first experiment, leaf area was assessed using 50 leaves harvested out of ten plants through digital image. This calculated value was then compared to leaf area estimation obtained using leaf disks. In addition, leaf area was correlated to the following leaf diagonals: main rib, perpendicular to the main rib, and two transversal measures to the main rib. A determination coefficient $\left(\mathrm{r}^{2}\right)$ of $0,94(\mathrm{p}<0,05)$ was obtained for leaf area calculated through digital images and leaf disks. The leaf area formula $0,8906 x^{2}$, where $x$ corresponds to the measure on the main rib, presented the largest determination coefficient $\left(r^{2}=0,99 ; p<0,05\right)$ among the four tested diagonals. In the second experiment, two plant densities were tested: $0.60 \times 0.50 \mathrm{~m}$ and $0.30 \times 0.25$ respectively between plants and rows. For each plant density, leaf area was estimated using the equation adjusted for the length of the main rib. Main rib was measured in all leaves larger than $5 \mathrm{~cm}$ of four plants. Logistics models were adjusted for leaf area and flower number variation in time. Flowers were harvested in $1 \mathrm{~m}^{2}$. The smallest plant density provided a leaf area for plant $\left(6932 \mathrm{~cm}^{2}\right)$, with maximum at 47 days after transplanting (DAT) and 695 degree-day (GD), larger than the largest density $(3129 \mathrm{~cm} 2)$, with maximum at 42 DAT and 622 GD. Blooming took place before plants reached the maximum leaf area and the largest flower production was obtained in the largest plant density.

Keywords: Tropaeolum majus, growth models, plant density.

(Recebido para publicação em 11 de novembro de 2005; aceito em 30 de abril de 2007)

$\mathrm{O}$ nastúrcio (Tropaeolum majus L.) planta da família Tropaeolaceae, é uma trepadeira anual, herbácea, com caule circular, folhas inteiras, peltadas, alternas e verdes, e flores grandes e vistosas, variando do amarelo ao vermelho (Martins et al., 1994). As folhas e flores têm sabor picante (compostos sulfurados), sendo de uso ornamental, alimentício e terapêutico. O nastúrcio é utilizado como digestivo, depurativo e cicatrizante, além de combater o escorbuto, devido ao alto teor de vitamina C (Martins et al., 1994).
As comprovadas propriedades medicinais do nastúrcio têm despertado enorme interesse em estudos na área fitoquímica. No entanto, estudos sobre aspectos agronômicos dessa planta são escassos no Brasil, apesar do nastúrcio ser uma excelente alternativa de cultivo para pequenos produtores, visando suprir as necessidades de restaurantes e da indústria farmacêutica. Em trabalhos recentes, foram encontradas relações importantes entre espaçamento e o crescimento de nastúrcio (Ferreira et al., 2000; Ramos et al., 2003). O espaçamento entre plantas afeta várias características associadas à produtividade das culturas, incluindo a produção de flores e a área foliar.

A área foliar é um dos parâmetros mais importantes na avaliação do crescimento das plantas, pois sua determinação adequada durante o ciclo da cultura possibilita modelar o crescimento e o desenvolvimento das plantas e, em conseqüência, a produtividade e a produção total da cultura (Teruel, 1995). Auxilia, ainda, na definição da época ideal de semeadura e transplante, uma 
vez que, se não for considerada a intervenção de outros fatores, as culturas devem ser semeadas de modo que os valores máximos do índice de área foliar coincidam com a época de elevada radiação, quando a fotossíntese líquida será máxima (Galvani et al., 2000).

Entre os métodos para determinar a área foliar, os não destrutivos permitem a repetição das medidas durante o período de crescimento, reduzindo alguns erros experimentais associados a procedimentos amostrais destrutivos (Nesmith, 1992). Os destrutivos, muitas vezes, limitam a quantidade de efeitos de tratamentos a serem estudados em um experimento, quando o número de plantas é limitado. O uso de equações de regressão para estimar a área foliar é um método não destrutivo, simples, rápido, preciso e confiável. O procedimento usual deste método envolve medidas do comprimento, largura e das áreas de amostras de folhas e, em seguida, a obtenção dos coeficientes de regressão que relacionam as medidas lineares com a área da folha (Wiersma \& Bailey, 1975). Preciso e simples, este método matemático elimina a necessidade do uso de medidores e reconstruções geométricas e reduz o tempo para medições (Gamiely et al., 1991).

O objetivo deste trabalho foi obter equações que permitam estimar a área foliar do nastúrcio por métodos não destrutivos, além de determinar a variação temporal da área foliar e do número de flores sob duas densidades de plantas.

\section{MATERIAL E MÉTODOS}

Foram conduzidos dois experimentos, de março a dezembro de 2003, na Universidade Federal de Santa Maria, em Santa Maria (2941'25" S, 5348'42" W, 95 m de altitude). Seu clima, de acordo com Köeppen, é do tipo Cfa, temperado chuvoso, com chuvas bem distribuídas ao longo do ano e subtropical do ponto de vista térmico. A temperatura média anual é de aproximadamente $19,3^{\circ} \mathrm{C}$ e umidade relativa média do ar de $78,4 \%$. Julho é considerado o mês mais frio, com valor médio das temperaturas mínimas de $9,3^{\circ} \mathrm{C}$ e, janeiro, o mês mais quente, com média das temperaturas máximas de $31,8^{\circ} \mathrm{C}$.
Os experimentos foram instalados no interior de estufa plástica de 10 × 25 m, modelo túnel alto (Santos, 2000), coberto com cloreto de polivinil (PVC) plastificado com espessura de 0,2 mm, aditivado contra os raios ultravioletas. As mudas de nastúrcio foram produzidas no substrato comercial Plantmax, em bandejas com 128 células, e também em espuma fenólica, com uma semente por cubo de 2' 2 ' $2 \mathrm{~cm}$, colocados em perfis de polipropileno por onde circulava a solução nutritiva recomendada para alface (Castellane \& Araújo, 1995), diluída para $25 \%$. A reposição de água foi feita diariamente e, a correção do $\mathrm{pH}$, a cada dois dias, mantendo-o entre 5,5 e 6,5. Quando necessário elevar o pH, utilizou-se hidróxido de sódio $(\mathrm{NaOH}$ 0,3N); para reduzi-lo, ácido sulfúrico $\left(\mathrm{H}_{2} \mathrm{SO}_{4} 10 \%\right)$. As mudas foram transplantadas com quatro a cinco folhas e altura em torno de $10 \mathrm{~cm}$ para canteiros de 6,70 x $0,90 \mathrm{~m}$, constituídos por calhetões de fibrocimento de $0,40 \mathrm{~m}$ de profundidade. Os canteiros foram preenchidos com mistura de substrato comercial Plantmax e solo, na proporção de 1:1, e cobertos com plástico dupla face, perfurados no espaçamento utilizado para as plantas. A irrigação foi realizada por gotejamento, com a inserção de espaguetes perfurados a cada $0,25 \mathrm{~m}$, logo abaixo do plástico dupla-face. Não foi utilizado nenhum defensivo químico.

Durante os dois primeiros meses do ciclo da cultura, utilizou-se a fertirrigação com solução para alface (Castellani \& Araújo, 1995), diluída a $50 \%$, e, após este período, foi utilizada a solução uma vez por semana, mantendo-se a cultura em condição não limitante de água. O primeiro experimento, realizado em março de 2003, foi conduzido em canteiro (calhetão com substrato) sob a estufa, até aproximadamente 45 dias de cultivo. Foram utilizadas 50 plantas, das quais foram sorteadas dez, de onde foram retiradas 50 folhas de diferentes tamanhos. As 50 folhas foram fotografadas individualmente com máquina digital e, após, foi determinada a área foliar pelo método destrutivo, utilizando discos foliares. As fotos foram processadas no programa computacional Sigma Scan Pro v. 5.0, Jandel Scientific, San Rafael, CA, para a obtenção da área de cada folha. A área foliar estimada a partir das imagens foi então relacionada àquela determinada pelos discos foliares, através do coeficiente de correlação de Pearson.

Para identificar a medida linear da folha que melhor estima a área foliar, utilizou-se a análise de regressão não linear, em que a área das 50 folhas obtidas por foto digital foi considerada a variável dependente e as medidas diagonais da folha, mensuradas com régua milimetrada, as variáveis independentes. As medidas diagonais foram: medida sobre a nervura principal (d1), perpendicular à nervura principal $(\mathrm{d} 2)$ e duas transversais à nervura principal (d3 e d4) (Figura 1). Diante das inúmeras funções ajustadas pelo programa Table Curve, os critérios para escolha das funções que melhor relacionam a medida linear com a área foliar foram menor número de parâmetros e maior coeficiente de determinação.

Para caracterizar a variação temporal da área foliar e do número de flores foi realizado um segundo experimento, com a produção de mudas realizada em maio de 2003. Foram utilizados quatro canteiros, com as mesmas condições do primeiro experimento, porém com duas densidades de plantio: 0,60 m entre plantas com 0,50 m entre linhas e 0,30 m entre plantas com $0,25 \mathrm{~m}$ entre linhas. De cada densidade foram sorteadas e marcadas quatro plantas, cujas folhas maiores que $5 \mathrm{~cm}$ de diâmetro tiveram a diagonal identificada no primeiro experimento como melhor estimador da área da folha mensurada com régua milimetrada, uma vez por semana até o início da produção de frutos. Com as temperaturas máximas e mínimas do ar do período pós-transplante calculou-se a temperatura média e os graus-dias acumulados, que, uma vez relacionados à área foliar de cada densidade, permitiram desenvolver modelos de crescimento.

Durante o florescimento foram marcadas aleatoriamente áreas de um metro quadrado em cada densidade de plantio, de onde as flores foram colhidas semanalmente, quantificando a sua produção, bem como a variação temporal do florescimento nas duas densidades de plantio. Utilizou-se o programa Table Curve 2D, Jandel Scientific, San 
Tabela 1. Equações exponenciais relacionando a área foliar (Y), obtida por foto digital, com quatro diagonais $\left(\mathrm{d}_{\mathrm{i}}\right)$ medidas em amostras de 50 folhas de nastúrcio (Exponential equations relating leaf area (Y), obtained by digital photos, with four diagonal measures (di) in samples of 50 nasturtium leaves). Santa Maria, UFSM, 2005.

\begin{tabular}{llc}
\hline Diagonais & Equações & $\mathbf{r}^{2}$ \\
\hline Sobre a nervura principal $\left(d_{1}\right)$ & $\mathrm{Y}=0,89006 \mathrm{~d}_{1}{ }^{2,0047}$ & 0,9981 \\
Perpendicular a nervura principal $\left(\mathrm{d}_{2}\right)$ & $\mathrm{Y}=0,9781 \mathrm{~d}_{2}{ }^{1,8726}$ & 0,9969 \\
$1^{\text {a }}$ transversal à nervura principal $\left(\mathrm{d}_{3}\right)$ & $\mathrm{Y}=0,9188 \mathrm{~d}_{3^{1,8960}}$ & 0,9957 \\
$2^{\text {a }}$ transversal à nervura principal $\left(\mathrm{d}_{4}\right)$ & $\mathrm{Y}=0,9908 \mathrm{~d}_{4}^{1,8679}$ & 0,9960 \\
\hline
\end{tabular}

* Significativo, $\mathrm{p}<0,05$ (significant, $\mathrm{p}<0,05$ ).

Tabela 2. Modelos logísticos de variação temporal da área foliar (AF) estimada de nastúrcio, em ambiente protegido, em função do número de dias após o transplante (DAT) e da soma térmica (GD) (Logistic models of estimation of leaf area (LA) variation in time, in greehouse, as function of number of days after the transplant (DAT) and thermal sum (GD)). Santa Maria, UFSM, 2005.

\begin{tabular}{llc}
\hline Densidade & \multicolumn{1}{c}{ Modelos } & $\mathrm{r}^{2}$ \\
\hline $0,60 \mathrm{~m} \times 0,50 \mathrm{~m} \quad \mathrm{AF}=4^{*} 6976,73^{*} \mathrm{n} /(1+\mathrm{n})^{2}$, em que: $\mathrm{n}=\exp (-(\mathrm{DAT}-47,21) / 14,42$ & 0,6636 \\
$0,30 \mathrm{~m} \times 0,25 \mathrm{~m} \mathrm{AF}=4^{*} 3144,57^{*} \mathrm{n} /(1+\mathrm{n})^{2}$, em que: $\mathrm{n}=\exp (-($ DAT-42,32)/16,81 & 0,6294 \\
$0,60 \mathrm{~m} \times 0,50 \mathrm{~m} \quad \mathrm{AF}=4^{*} 6932,09^{*} \mathrm{n} /(1+\mathrm{n})^{2}$, em que: $\mathrm{n}=\exp (-(\mathrm{GD}-695) / 217,43$ & 0,6630 \\
$0,30 \mathrm{~m} \times 0,25 \mathrm{~m} \mathrm{AF}=4^{*} 3128,75^{*} \mathrm{n} /(1+\mathrm{n})^{2}$, em que: $\mathrm{n}=\exp (-(\mathrm{GD}-622) / 252,80$ & 0,6239 \\
\hline
\end{tabular}

* significativo, $\mathrm{p}<0,05$ (significant, $\mathrm{p}<0,05$ ).

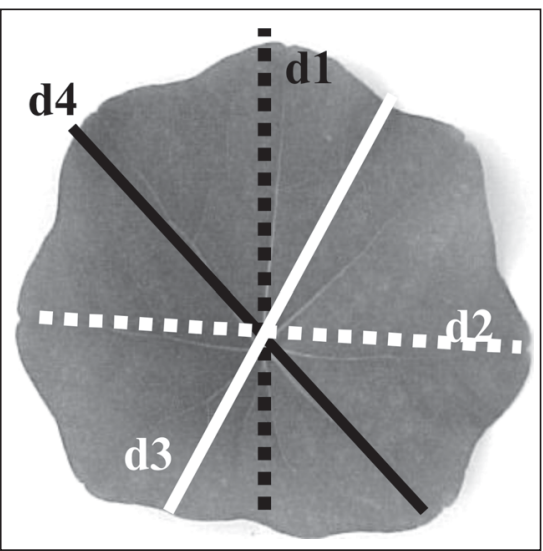

Figura 1. Folha de nastúrcio com quatro diagonais (d1, d2, d3 e d4) utilizadas como variáveis independentes para estimar a área foliar (Nasturtium leaf with the four diagonals - d1, d2, d3, and d4 - used as independent variables to estimate leaf area). Santa Maria, UFSM, 2005.

Rafael, CA, para encontrar os modelos que relacionam o número de flores ao número de dias após o transplante, com os mesmo critérios de ajuste adotados no primeiro experimento. Além destes critérios, os modelos ajustados entre área foliar e soma térmica e área foliar e dias após o transplante seguiram o pressuposto de que a variação temporal da área foliar deve apresentar um crescimento de forma sigmoidal.

\section{RESULTADOS E DISCUSSÃO}

Relacionando-se as medidas obtidas pelo método destrutivo, por meio de discos foliares, com as medidas obtidas pelas fotos digitais, obteve-se coeficiente de determinação $\left(\mathrm{r}^{2}\right)$ de $0,94(\mathrm{p}<0,05)$, sendo vantajosa a utilização das imagens digitais pela rapidez, facilidade e por não constituirem um método destrutivo. Deve-se ressaltar que a utilização de discos foliares tem sido contestada para mensuração de área foliar, pois na comparação com o método de referência LICOR, na cultura do cafeeiro, a utilização de discos foi considerada menos precisa e exata (Tavares Júnior et al., 2002).

Relacionando as medidas diagonais da folha com as respectivas áreas foliares obtidas pelas fotos digitais, obteve-se um modelo exponencial para cada diagonal (d1, d2, d3 e d4) (Tabela $1)$, todos com bom ajuste $\left(r^{2}>0,99\right)$, indicando que todos os modelos podem ser utilizados para estimativa da área foliar do nastúrcio (Figura 1). Queiroga et al. (2003), trabalhando com feijãode-vagem, também obtiveram melhor ajuste $\left(r^{2}=0,98\right)$ e precisão para a estimativa da área foliar através de modelo exponencial, utilizando como variável independente a largura do folíolo central. Já para a espécie Tridax procumbens, a função exponencial foi a que menos explicou a relação entre a área foliar e o produto do comprimento pela largura da folha, com $\mathrm{r}^{2}$ de aproximadamente 0,80 (Bianco et al., 2004). A precisão de equações para estimativa de área foliar, dentre as várias possibilidades de combinações entre parâmetros dimensionais e modelos de regressão, relaciona-se não só com o formato da folha, mas também com sua variação durante o crescimento da planta. Vale ressaltar que a variação da forma da folha é uma característica da espécie e está associada às condições ambientais de crescimento, como foi observado em Lycopersicon esculentun (Dumas, 1990) e Curcubita pepo L. (Silva et al., 1998).

Para a estimativa da variação temporal da área foliar em função de dias após o transplante (DAT), utilizou-se a equação ajustada para o diâmetro medido sobre a nervura principal (d1). Segundo os critérios pré-estabelecidos, ou seja, menor número de parâmetros, maior coeficiente de determinação e crescimento de forma sigmoidal, ajustou-se o modelo logístico: Área Foliar $=4 * a * n /(1+n)^{2}$, em que: $\mathrm{n}=\exp (-(D A T-$ b)/c). Os parâmetros "a" e "b" do modelo têm algumas interpretações biológicas associadas, em que o parâmetro "a" representa o valor máximo esperado para a variável-resposta e, o "b", é o valor da variável independente correspondente ao máximo da variável resposta (Tabela 2).

Na menor densidade $(0,60 \times 0,50 \mathrm{~m})$, encontrou-se maior área foliar por planta do que na maior densidade $(0,30 \times 0,25$ m) (Figura 2a). A menor área foliar encontrada na maior densidade pode ser explicada pela maior competição entre plantas por luz, água e nutrientes, sendo que o máximo da área foliar ocorreu aos 47 e 42 dias após o transplante (DAT) para as densidades $0,60 \times 0,50$ m e $0,30 \times 0,25 \mathrm{~m}$, respectivamente. Os resultados encontrados concordam com Ferreira (2000) que, analisando características do crescimento de nastúrcio, cultivar Jewel, sob os espaçamentos de 0,20; 0,30 e 0,40 m entre plantas e 0,60 $\mathrm{m}$ entre fileiras, encontrou maior área foliar $\left(15.000 \mathrm{~cm}^{2}\right)$ para plantas culti- 


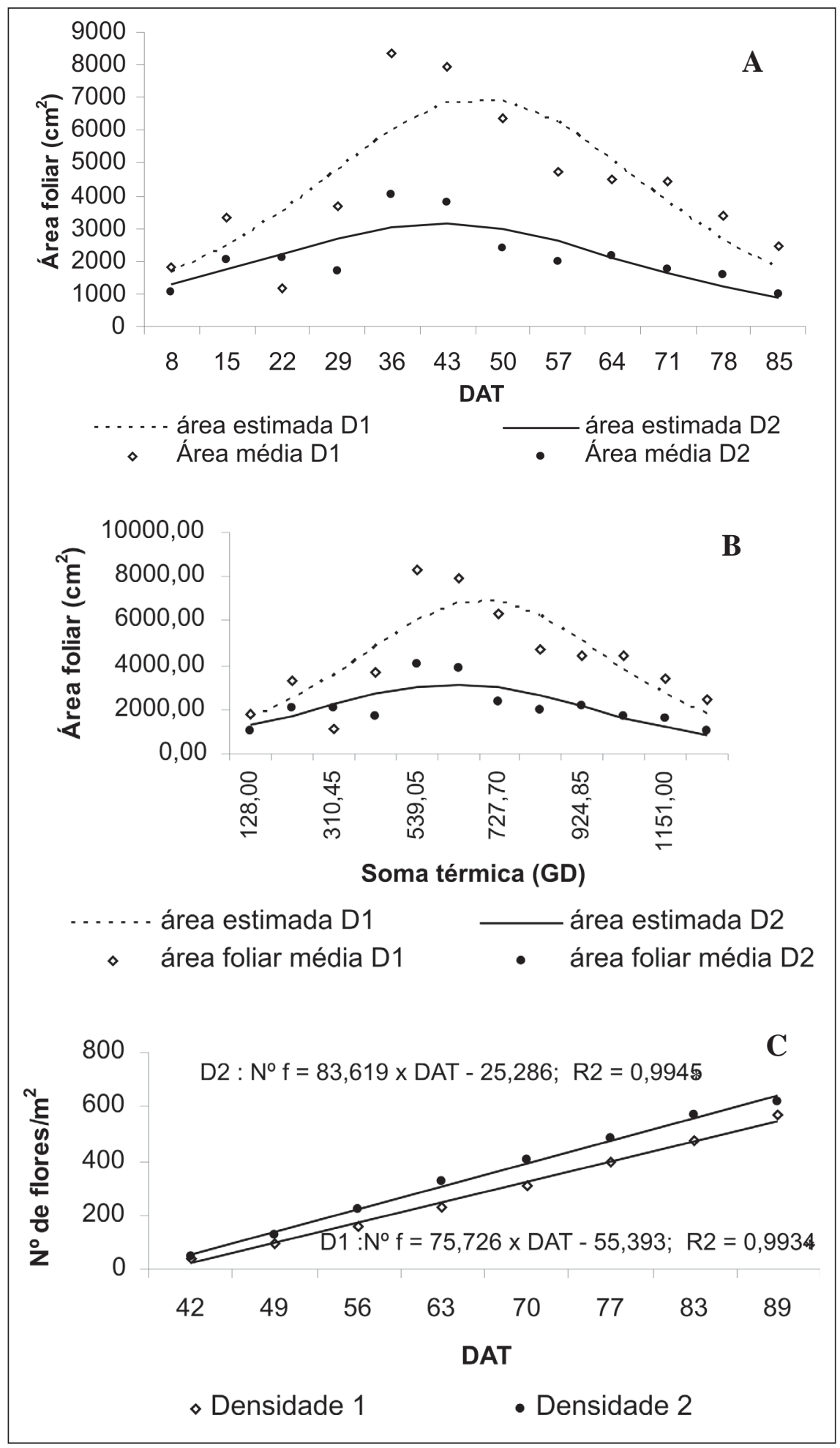

Figura 2. Variação temporal da área foliar e do número de flores de nastúrcio para duas densidades de plantio: $0,60 \times 0,50 \mathrm{~m}$ (D1) e $0,30 \times 0,25 \mathrm{~m}$ (D2) (Leaf area and flower number variation in time for two planting densities: $0,60 \times 0,50 \mathrm{~m}$ (D1) and 0,30 x 0,25 m (D2). Santa Maria, UFSM, 2005.

vadas no espaçamento de $0,30 \mathrm{~m}$ entre plantas. No entanto, a autora observou o máximo da área foliar 105 DAT.

$\mathrm{O}$ modelo de crescimento que estimou a área de folha por planta, para os dois espaçamentos em função da variável independente graus-dia (GD), foi o mesmo modelo da relação área foliar e dias após o transplante (Figura 2b). A soma térmica necessária para o nastúrcio atingir o máximo crescimento vegetativo variou de acordo com a densidade considerada, sendo que, na maior densidade, as plantas atingiram a máxima área foliar $\left(3129 \mathrm{~cm}^{2}\right)$ com menor soma térmica (622 GD) do que na menor densidade (695 GD), em que obteve uma área foliar máxima estimada de $6932 \mathrm{~cm}^{2}$. Segundo Lyra et al. (2003), o empirismo, associado à variável independente DAT, limita a aplicação dos resultados para condições ambientais semelhantes. Dessa forma, a utilização da soma térmica permite maior generalização dos resultados.

Relacionando-se o número de flores produzidas do $42^{\circ}$ até $89^{\circ}$. DAT obtiveram-se equações lineares simples (Figura 2c). Na menor densidade $(0,60 \mathrm{x}$ $0,50 \mathrm{~m}$ ), o florescimento teve início antes da planta atingir a área foliar máxima e, apesar da maior área foliar por planta em relação à maior densidade (0,30 x 0,25 m), o número de flores produzidas foi menor. $\mathrm{O}$ fato da produção máxima de flores por área ter sido obtida na maior densidade de plantas indica que a competição entre plantas existente não foi suficiente para reduzir o número de flores. Considerando-se que a flor é o produto final desejado, é importante verificar que é possível produzir maior quantidade de flores em menor espaço, fato que está de acordo com a necessidade de otimização de espaço disponível em ambiente protegido.

Com relação ao número de dias até o florescimento, Ferreira (2000) encontrou resultado semelhante utilizando o nastúrcio, cultivar Jewel, onde o início do florescimento ocorreu 45 DAT e, de frutificação, 70 DAT. Já em trabalho avaliando a produção de flores da cultivar Jewel sob populações de 80.000; 100.000 e 120.000 plantas ha ${ }^{-1}$ e arranjos de plantas em duas ou três fileiras simples no canteiro $(0,54 \mathrm{~m}$ entre duas e $0,36 \mathrm{~m}$ entre três fileiras), a autora observou que a produtividade de flores $\left(\mathrm{n}^{\mathrm{o}}\right.$ flores planta $^{-1}$ ) não foi influenciada por estes tratamentos. No entanto, houve incremento na produção da massa seca de frutos na menor população e, apesar da produtividade de flores ser semelhante para as populações e arranjos estudados, a autora indicou o arranjo de plantas em duas fileiras como o 
mais adequado, com a finalidade de facilitar a operação de colheita para o agricultor. Ramos et al. (2003) também não encontraram influência do espaçamento no número e massa seca de flores do nastúrcio para os espaçamentos de 0,30 e $0,40 \mathrm{~m}$ entre plantas e $0,36 \mathrm{~m}$ entre fileiras.

Os resultados apresentados neste trabalho permitem concluir que: as medidas sobre a nervura principal, perpendicular à nervura principal e as duas medidas transversais à nervura principal, podem ser utilizadas para estimativa da área foliar de nastúrcio; quanto menor a densidade de plantio maior é a área foliar por planta e mais tempo a planta leva para atingir o crescimento máximo; e, o florescimento ocorre antes da planta atingir o máximo da área foliar, enquanto que a maior produção de flores por área é obtida na maior densidade de plantas, mesmo com menor área foliar por planta.

\section{REFERÊNCIAS}

BIANCO S; PITELLI RA; CARVALHO LB 2004. Estimativa da área foliar de Tridax procumbens usando dimensões lineares do limbo foliar. Planta Daninha 22: 247-250.
CASTELLANE PD; ARAÚJO JAC. 1995. Cultivo sem solo: hidroponia. Jaboticabal: FUNEP. $43 \mathrm{p}$.

DUMAS Y. 1990. Interrelation of linear measurements and total leaf area or dry matter production in young tomato plants. Advances in Horticultural Science 4: 172-176.

FERREIRA RBG. 2000. Crescimento, desenvolvimento e produção de flores e frutos da capuchinha 'Jewel' em função de populações $e$ de arranjos de plantas. Campo Grande: UFMS. 68p (Dissertação mestrado).

GALVANI E; ESCOBEDO JF; CUNHA AR KLOSOWSKI ES. 2000. Estimativa do índice de área foliar e da produtividade de pepino em meio protegido - cultivo de inverno e de verão. Revista Brasileira de Engenharia Agrícola e Ambiental 4: 8-13.

GAMIELY S; RANDLE WM; MILLS HA SMITTLE DA. 1991. A rapid and nondestructive method for estimating leaf area of onions. Hort Science 26: 206.

LYRA GB; ZOLNIER S; COSTA LC; SEDIYAMA GC; SEDIYAMA MAN. 2003. Modelos de crescimento para alface (Lactuca sativa L.) cultivada em sistema hidropônico sob condições de casa-de-vegetação. Revista Brasileira de Agrometeorologia 11: 79-84.

MARTINS ER; CASTRO DM; CASTELLANI DC; DIAS JE. 1994. Plantas medicinais. Viçosa: UFV. 220p.

NeSMITH DS. 1992. Estimating summer squash leaf area nondestructively. Hortscience 27: 77.
QUEIROGA JL; ROMANO EDU; SOUZA JRP; MIGLIORANZA, E. 2003. Estimativa da área foliar do feijão-vagem (Phaseolus vulgaris L.) por meio da largura máxima do folíolo central. Horticultura Brasileira 21: 64-68.

RAMOS MBM; MANTOVANELI MCH; VIEIRA MC; ZÁRATE NAH; BARROS, EO; SILVA CAA; TEIXEIRA IR. 2003. Produção de flores e de frutos de Tropaeolum majus $\mathrm{L}$. em função de espaçamentos entre plantas e uso de cama-de-aviário. In: CONGRESSO BRASILEIRO DE OLERICULTURA, $43^{\circ}$. Resumos...Recife: SOB (CD-ROM).

SANTOS OS. 2000. Hidroponia da alface. Santa Maria: UFSM. 80p.

SILVA NF; FERREIRA FA; FONTES PCR; CARDOSO AA. 1998. Modelos para estimar a área foliar de abóbora por meio de medidas lineares. Revista Ceres 45: 287-291.

TAVARES-JÚNIOR JE; FAVARIN JL; DOURADO-NETO, D; MAIA AHN; FAZUOLI LC; BERNARDES MS. 2002. Análise comparativa de métodos de estimativa de área foliar em cafeeiro. Bragantia 61: 199-203.

TERUEL DA. 1995. Modelagem do índice de área foliar da cana-de-açúcar em diferentes regimes hídricos. Piracicaba: USP-ESALQ. 93p (Dissertação mestrado).

WIERSMA, JV; BAILEY TB. 1975. Estimation of leaflet, trifoliate, and total leafs areas of soybeans. Agronomy Journal 67: 26-30. 